\title{
Italian healthcare organizations facing new dimensions: changes in governance structure
}

\author{
Anna Romiti ${ }^{1} \cdot$ Mario Del Vecchio $^{1,2} \cdot$ Chiara Milani $^{3} \cdot$ Gino Sartor $^{4}$ (D)
}

Accepted: 12 December 2021

(c) The Author(s) 2022

\begin{abstract}
Private and public organizations facing merger processes may consider reconfiguring the size, composition, and mechanisms used by the strategic apex. In Italian local health organizations (LHOs), the strategic apex had to face challenges arising from an increase in size and its impacts on different governance areas. The aim of this study is to highlight the role of the top management team in shaping the conditions of governance, and link these conditions to certain internal and external characteristics of the specific LHO and to the behavior and vision of the CEO. The study used qualitative techniques to examine the cases of three of the largest Italian LHOs that had undergone merger processes in recent years. The results show how changes in the organizational size impact the structure and mechanisms of the strategic apex. In particular, this study identifies three main governance strategies.
\end{abstract}

Keywords Strategic apex · Corporate headquarters · Public healthcare organization Merger · Governance areas · Corporate governance

\section{Introduction}

Within the management field, the study of governance is a much-discussed topic, which focuses primarily on decision-making by boards and top managers, as well as on the organizational environment in which these decisions take place. Research in this field is moving beyond the traditional area of agency conflict between owners

Gino Sartor

gino.sartor@yahoo.it

1 Health Services Research Unit, Department of Experimental and Clinical Medicine, University of Florence, Florence, Italy

2 SDA Bocconi School of Management, Milan, Italy

3 Department of Health Science, University of Florence, Florence, Italy

4 School of Specialization in Hygiene and Preventive Medicine, University of Florence, Florence, Italy 
and management. New perspectives on governance consider managers as leaders rather than as mere agents of shareholders, and consider contexts including nonprofit and public organizations. Moreover attention is shifting from incentive alignment to organizational architecture, coordination, and collaboration; however, further research on this topic, such as comparative analysis of governance forms and their impact on managerial and organizational processes and changes in governance over time, is warranted (Tihanyi et al., 2014).

In the current study we concentrate, in a general context of change, on the role that the CEO and top managers can play when the corporate structure of a public organization does not foresee the presence of a board. This positions our study at a crossroad from most of the aforementioned perspectives. In particular, our study offers additional evidence through an empirical analysis of the role of organizational architectural and leadership roles in corporate governance.

The importance of the lens of change that we adopted cannot be undervalued. It allows for better observation of the nature of phenomena (the change in governance over time) even if the primary focus is on non-temporal issues (Ancona et al., 2001). Thus, observations regarding what happened before change can be useful in the analysis, even if the main framework is comparative in nature. In our case, the source of change is merger processes and the following increase in size that may lead to the reassessment of governance systems in terms of organizational design, configuration of the top management team (TMT), and/or the corporate headquarters (CHQ).

Italy is an emblematic case for the analysis of governance issues in public organizations in the context of radical change. In the Italian National Health System, local health organizations (LHOs) are responsible for providing all healthcare services to the population, both directly and by buying services from other independent public and private providers. In the last 5 years, many LHOs have gone through mergers, doubling the size of some LHOs to service more than 1.5 million community members, with budgets over one billion euros (Barzan et al., 2018).

The governance framework in all Italian LHOs is centered around a general director (GD), selected and appointed by the regional government, and endowed with full legal and managerial powers. The GD figure is the result of an important reform that, in the early nineties, replaced the previous boards of management and clinical and administrative coordinators with monocratic general managers who were responsible for the results achieved (Toth, 2015). The GD appoints a Clinical Director (CD; Italian: Direttore Sanitario) and an Administrative Director (AD; Italian: Direttore Amministrativo). Together, they form a triad that represents the formal governing authority of each LHO (and public independent hospitals) (Kirkpatrick et al., 2013; Terlizzi, 2019). In this article, we refer to the triad as the TMT, and we refer to the GD with the term CEO. Even within the constraints of the regional government policy (Ashburner, 2003), the triad may cover part of the roles and functions that in other healthcare organizations and systems (Chambers et al., 2020; Lee et al., 2008) are under the responsibility of a board.

The formal structure of the TMT is regulated by law, but organizations can differ in the governance approaches, strategic choices, relationships with stakeholders, and 
decision-making processes adopted by the TMT, as well as in the size and composition of the CHQ (Morelli \& Lecci, 2014).

The pivotal role that the reform of the early nineties assigned to the TMT, and to the CEO in particular, addressed a dual need. On the one hand, since the postreform institutional framework gave the regional government greater financial and political risk, the appointment of top management allowed them to exert more direct control on the LHOs. Moreover, this appointment of TMTs by regional governments restrained the influence of municipalities on LHOs. On the other hand, a reasonably strong level of unity of command had to be established in organizations that were exposed to public and professional pressures during this time (Mintzberg, 2012). The choice of having a single individual in charge (the CEO appointed by the regional government) was largely based on the need for a clearer and tighter line of accountability, both upward and downward.

With this shift from a hypothetical board to a CEO, the issue of dealing with external stakeholders and incorporating different points of view in the decisionmaking processes became more pronounced. In fact, the permeability to the environment typical of a public healthcare organization, the persistent role of municipal governments and local communities, and the degree of institutional autonomy allowed LHOs to offer a potentially strategic space in terms of both decision-making and implementation (Del Vecchio, 2000).

In the last 5 years, the tendency toward a reduction in the number of LHOs and an increase in the size of their average target population, has visibly, and in certain regions brusquely, accelerated, impacting all the areas that demand the attention of the TMT. A larger LHO means an increase in the number of external actors, as well as in the volume of services to be produced. At the same time, the corporate governance structure of LHOs, centered on the CEO and triad, has not changed since the'92 reform. Notwithstanding the substantial amount of autonomy that regions enjoy in designing their systems, it remains the only governance structure allowed for public healthcare organizations, irrespective of their size and mission (Del Vecchio \& Romiti, 2017).

In this context of lean (absence of a board) and fixed (impossibility to introduce changes) corporate governance structures, many TMTs had to face the challenges arising from the size increases and their impacts on different governance areas. An observed readjustment in the TMT functioning after a merger process signals how potential imbalances between the demand and supply of governance in different areas are perceived and solved by the CEO.

The literature underlines that the attention of a board, as a part of a given governance structure, may focus on different areas of governance (Edwards \& Cornforth, 2002). In particular, Lee et al. (2008) identified a governance healthcare board taxonomy, reflecting different perceptions about roles to be performed, including: acting as a policy maker to define the LHO's mission and strategic direction, building and maintaining relations with key external actors, supervising organizational and managerial performance and assuming the role of boundary spanner. Their research identified differences in the organizational and environmental conditions linked to different areas of focus. 
Much less clear is how areas can be defined when, in the absence of a board, they are the sole responsibility of the TMT. Additionally, it is unclear how the overall functioning of the LHO changes after an increase in internal and external complexity (Alexander, 1991; Foss, 1997). From this perspective, the current study is a response to calls for developments in our understanding of how governance structure and processes may be linked to the specific contexts in which they take place (Chambers et al., 2020; Erwin et al., 2019).

The study analyzes governance processes in public healthcare organizations, paying particular attention to how governance needs may change as a result of fundamental changes in the size and structure of the organization; therefore, TMT needs to change its focus. Previous research has pointed to the idea that governance needs have to be adapted to different contexts (Chambers et al., 2020; Erwin et al., 2019); however, this topic is considered widely unexplored in the public management and corporate governance fields (Ferlie et al., 2003; Forbes \& Milliken, 1999; Veronesi \& Keasey, 2010).

We argue that the TMT may choose specific governance mechanisms in addition to targeted areas of focus. Such choices cannot be fully understood without considering the perspective of the TMT on two aspects: the level of internal control required by the organization and the complexity of the external environment. The aim of this study is to highlight the role of the TMT in shaping the actual conditions of governance and link them to specific internal and external characteristics of the LHO and to the behavior and vision of the CEO.

To achieve this aim, this study has two objectives. The first objective is to investigate the governance approaches adopted by TMTs of LHOs that have undergone merger processes. The second objective is to investigate the reasons behind the differences in how TMTs of different LHOs interpret and play their roles in monocratic governance systems. To achieve these objectives, we used the cases of three Italian LHOs (Rome 1, City of Turin, and Central Tuscany), which after merger processes were among the largest LHOs in the nation.

Our research questions are: (1) what are the governance areas that call for attention from TMTs as main actors in the governance framework of public healthcare organizations; (2) what are the possible strategies that a TMT may adopt facing the challenges arising from different areas of governance; (3) what are the antecedents of these choices in terms of objective characteristics (a particular internal and external organizational context) or subjective characteristics (management style, perceptions of the actors about their governance role).

This paper is structured as follows: first, we will review the existing literature on boards and strategic apexes in private and public organizations, with a focus on TMTs and CHQs; then, we will articulate the methodology of our study, followed by a description of the cases. Next, we will analyze the impacts of mergers on governance structures and areas chosen by the TMTs. Finally, we conclude the article by summarizing our key findings. 


\section{Literature review}

\subsection{Top management and boards in the governance structure of the public healthcare organizations}

Governance of organizations is usually the joint result of the efforts of boards and top managers in their strategic roles (Cornforth, 2003). As we have already mentioned, in the case of LHOs, TMTs play the dual role of board as well as of strategic apex; thus, relevant literature came from two different fields. One field of literature concerns the role of boards in the corporate governance framework, and the other concerns the strategic function of the TMT. Since the CHQ supports the TMT in covering the range of its responsibilities, in the case of LHOs, the role of the CHQ became fundamental in terms of governance processes.

Although many studies converge on the importance of jointly analyzing the different components of governance processes and structures, the literature has mainly focused on the analysis of distinct elements of governance, such as board size and composition (Alexander \& Lee, 2006; Golden \& Zajac, 2001; Goodstein \& Boeker, 1991; Young et al., 1992) or on the relationship between governance structure and performance (Lee et al., 2008). These studies rarely address the issue of the complementarity and overlap in the roles played by the different actors (CEO, TMT, board) of the corporate governance structure, even if other studies of the public sector (Harris, 1992) argue that the analysis of the roles of boards and managers cannot be separated because of their interconnection and interdependence. In the same sector, Cornforth (2003) describes the nature of governance in public and nonprofit organizations as paradoxical, highlighting some tension between the board's role in monitoring and controlling the management and the importance of the partnership between the board and management. In public and nonprofit organizations, other tensions may arise considering the role of the board in assuring organizational effectiveness in partnership with the management (internal focus), and its role in "ensuring democratic accountability, transparency and adherence to government policy and performance" (external focus) (Edwards \& Cornforth, 2002).

It is important to note that, in the case of dual frameworks or monocratic frameworks, as in the Italian case (Toth, 2015), roles played and priorities considered in governance processes can vary depending on different internal and external factors. Lee et al. (2008) described different roles (mission/strategic setting, organizational performance and management team evaluation, and external relations) for healthcare organizations' boards based on different perceptions and differences in organizational and environmental conditions. Further, Dossi et al. (2017) confirm the importance of taking into account what they call the internal institutional environment in their analysis of the managerial consequences of acquisition processes in healthcare organizations. They show how healthcare organizations that face the same external institutional environment implement different internal steering modes as a consequence of the prevalent focus chosen by the TMT on planning and control mechanisms. 
In conclusion, research investigating the governance of healthcare organizations shows the importance of looking at both external and internal environments and recommends that scholars adopt a contingency approach because governance structures and processes cannot be standardized (Alexander, 1990). This is especially relevant in contexts such as the Italian one, characterized by a regionallybased healthcare system, and where the headquarters of healthcare organizations face many different regulatory and competitive environments (Dossi et al., 2017).

\subsection{The size and structure of $\mathrm{CHQ}$ and the increase of dimensions}

Change, defined as "an empirical observation of difference in form, quality of state over time in an organizational entity" (Van de Ven \& Poole, 2002, p. 512), is a useful lens for observing the governance structures and processes, and an increase in size through a merger is one of the most important changes that can impact corporate governance (Ancona et al., 2001). Mergers and acquisitions are usually associated with changes in the strategic apex (Menz, 2012). In this article, we refer to the TMT and CHQ as the strategic apices of an organization (Mintzberg, 1993). Before analyzing modifications in the strategic apexes that follow a change in the size of the organization, we will define the strategic apex and explore the choices about CHQ structure and roles that the TMT makes in response to an increase in the complexity of the organization.

An appropriate starting point for this discussion would be a definition of what a TMT is. As reported by Carpenter et al. (2004), this definition may range from generic definitions such as "top managers involved in strategic decision-making as identified by the CEO," to more specific ones such as "the CEO and direct reports" and the "top two tiers of an organization's management." For the purpose of this study, we define a TMT as individuals who are actively involved in the provision of strategic direction (Ambos \& Müller-Stewens, 2017).

One of the roles of the TMT is to design the structure of the CHQ, the CHQ being one of the main organizational supports for the subsequent actions of the TMT. The term CHQ refers to the staff and executive management team who are responsible for the whole, or majority of, the company (Collis et al., 2007). According to this definition, the CHQ includes "staff involved in general management, legal, financial reporting and control, treasury, and taxation activities" (Collis et al., 2007, p. 385). Notwithstanding its importance, "few studies have investigated the role of headquarters in a systematic way, and little is known about the extent and type of activities headquarters undertake in relation to the [dimensional] complexity" (Ciabuschi et al., 2012, p. 214).

There is a large variety of labels that authors have used to refer to the CHQ, including the strategic apex, central administrative office, corporate center, corporate parent, and headquarters, as reported by Kunisch et al. (2015). Very often, each label implies different assumptions regarding the composition of the CHQ. Following Young and Goold (1999), we adopted a definition of CHQ that does not include the TMT. This allowed us to analyze the decisions made by the TMT regarding the composition and size of the CHQ to cope with new complexities. In this article, we 
interchangeably use the terms strategic apex and corporate center to include both the TMT and CHQ.

The concept of the CHQ has been extensively debated in recent times. Ambos and Müller-Stewens (2017) highlight the need for further efforts in terms of the role of institutional context in determining the structure of the CHQ, and further suggest the use of longitudinal studies to enhance our understanding of the dynamics of corporate management.

The existing literature on CHQs and the corporate center of a firm can be divided into two groups (Kunisch et al., 2015): (a) studies that have analyzed the strategic domain (i.e., how the center manages the company in terms of roles/functions and styles), and (b) studies that have analyzed the organizational design of the center by examining the CHQ as a unit that heads the organization (formal and informal designs of the CHQ). In both groups, studies have focused on the antecedents of the changes that have taken place in corporate centers. We review the literature on the basis of this framework that we use for the case analysis description in the next section.

\subsubsection{Corporate center and strategic domain}

According to Chandler (1991), the corporate center has two principal roles: entrepreneurial (value creation) and administrative (loss prevention). He has also identified a third role, which is political in nature, and is designed to govern external relationships with shareholders. Other research (Young \& Goold, 1999) has identified a fourth role, which pertains to the centralized provision of services for operative units. Collis et al. (2007) examined the determinants of the size of a corporate center and summarized the different roles of a corporate center, including the following: control over financial and operational results, definition of priorities to create value, relationships with external stakeholders, and the provision of services that are central to the functioning of the entire company.

Goold and Campbell (1987) found that corporate centers may adopt three different steering modes: strategic planning, strategic control, and financial control. They found that each of these styles influences the size and structure of a CHQ. These styles have also been used to describe the management of healthcare organizations (Dossi et al., 2017). With regard to the strategic planning style, the center plays a pivotal role by focusing on planning and strategic processes that pertain to local plans and decisions. On the other hand, when it comes to strategic control style, the center focuses on reviews of plans developed by business unit managers. Finally, with regard to the financial control style, the center exercises control by means of budgetary processes and the decentralization of planning. The authors' conclusions adhere to a contingency approach: no style is superior to others, and each organization must find the best fit for their needs. 


\subsubsection{Corporate center and organizational design}

Studies on organizational design have examined the formal and informal structures of corporate centers, the level of centralization, and the relationships between corporate centers and other organizational levels (Alexander, 1991; Pettigrew, 1987). One of the roles of the corporate center is to "alter the responsibilities and duties of division managers in response to external or internal change" (Foss, 1997, p. 327). Accordingly, the same authors postulated that a standard model for successful CHQ does not exist. However, some differentiating factors have been identified: "the size of the company, the amount of functional influence exerted by the headquarters, the level of linkages between businesses in the portfolio, and the corporate policy on shared services" (Goold et al., 2001, p. 84).

Studies have also examined corporate centers from a dynamic perspective to analyze the changes that have taken place in a CHQ such as a change in the levels of formalization or in the extent of centralization, as studies by Kunisch et al. (2015). Generally, a redesign of the corporate center is largely attributable to the need to design the structure of an organization "that responds to the specific needs of the company and is fit for the purpose it is intended to serve" (Goold et al., 2001, p. 83). "The corporate center redesign represents an important component of many new corporate strategies and transformation processes," (Goold et al., 2001, p. 89) such as mergers and acquisitions (Menz, 2012). Mergers and acquisitions can lead to two competing approaches (Kunisch et al., 2015). Specifically, the first approach aims to strengthen central control and authority, whereas the objective of the second approach is to reinforce local autonomy and facilitate decentralization by providing those who belong to the operating level with greater authority (Ferlie \& Pettigrew, 1996). Previous research has identified the possible motivations that may underlie the decentralization of power and downsizing of the CHQ: "Possible explanations for such downsizing include responding to bottlenecks at the top [TMT] caused by over-centralization; the decentralizing effects of new information technology; the need to respond to more differentiated local markets; a more rapid pace of market change and the emergence of more sophisticated customers requiring more rapid local responses" (Ferlie \& Pettigrew, 1996, p. 498).

Changes in the CHQ are linked to strategic changes that have been caused by several factors: modification of the environment and its levels of complexity (Alexander, 1991), strategy (Cibin \& Grant, 1996), and the dominant coalition and its mode of governance. Growth that results from mergers and acquisitions can necessitate cultural changes, which can be facilitated by creating changes in the CHQ (Maljers, 1992). In such cases, change in the CHQ can be considered "as part of a wider organizational 'transformation' in which structures, roles and styles suddenly shift simultaneously throughout the organization" (Ferlie \& Pettigrew, 1996, p. 509).

In our study, we used a contingency approach, which suggests that the reconfiguration of a strategic apex depends on the environmental and organizational context (Donaldson, 2001), and that the role of the CHQ is contingent on the type and degree of change experienced by the internal and external environments (Foss, 1997). 
The last observation concerns the types of organizations we chose for our study. Eeckloo et al. (2007) raised questions about whether, and to what extent, the governance models of corporate companies and hospitals can be compared. In pluralistic settings, typical of hospitals and healthcare organizations, decision-making is an elaborate activity that includes multiple actors and decision processes (Jarzabkowski et al., 2007). Such organizations are often characterized by the dispersion of power and plurality of actors. The locus of the decision-making process (i.e., where decisions take shape) is substantially more diffuse in these environments than in most other organizations (Eeckloo et al., 2007). These characteristics and difficulties are accentuated by the institutional nature of many healthcare organizations involved in the provision of hospital- and community-based care services. In such an internal and external pluralistic environment, the TMT task of defining and leading the organization toward its goals and performance targets is overly complex (Carver, 2006), and this may offer a remarkably interesting opportunity to examine governance in action.

\section{Methodology}

\subsection{Study design and data collection}

The study analyzed the governance structures of three LHOs in three different regions that had undergone mergers. We adopted a multiple case study design with sequential data collection (Eisenhardt, 1989; Yin et al., 1983) because it is particularly suitable for use in investigations that aim to examine the complexity of healthcare systems, using in-depth analyses of the organizations and actors involved. The project involved the three LHOs (the cases) and for each of these data were collected individually and sequentially in a comparable way. The case study selection was performed according to the following steps (Yin, 2009). First, preliminary research was conducted to identify the cases that met the inclusion criteria (serve a large metropolitan area, be located in a capital city of the region, and have experienced a recent merger). Then, a meeting with a group of CEOs belonging to different Italian LHOs was held to share the research project structure. The meeting with the CEOs also allowed us to define the protocol for the CEOs' interviews. This protocol was tested in a pilot case and then submitted to the other two cases through a sequential data collection case study design (Appendix).

In the first phase of the research, we analyzed the legal and planning frameworks that define the governance and institutional structures of LHOs. Subsequently, we examined specific documents (company acts, organizational charts, and balance sheets) concerning the three LHOs to understand each organizations and their economic and financial structures. All of the documentation referred to both the premerger (including all of the documents of each LHO that have been merged) and post-merger period. The latter were considered to be the latest documents available.

During the second phase of the study, we interviewed the CEOs of the three LHOs using face-to-face semi-structured interviews. The interview protocol was designed from the first phase. It was designed in accordance with literature review, 
Table 1 Interviewed subjects, by role and LHO

\begin{tabular}{llll}
\hline Role & Rome 1 LHO & $\begin{array}{l}\text { Central Tuscany } \\
\text { LHO }\end{array}$ & $\begin{array}{l}\text { City of } \\
\text { Turin } \\
\text { LHO }\end{array}$ \\
\hline CEO & 1 & 1 & 1 \\
Staff director & 2 & 2 & 3 \\
Chair of department or clinical area & 4 & 4 & 2 \\
Head of operating units & 2 & 1 & 1 \\
Total number of interviewees & 9 & 8 & 7 \\
\hline
\end{tabular}

especially the parts that focused on the strategic apex in private and public organizations (TMTs and CHQs). We asked the CEO to describe the characteristics of their LHO (size, number of employees, percentage of the population that had been served, and number of hospitals and districts) and the rationale behind any changes in governance that occurred after the merger process. To address the research questions, middle managers (chairs of departments and clinical areas, and the heads of operating units) and staff directors were interviewed. We also interviewed middle managers in order to check the reliability of the CEO interviews and to obtain their perceptions about governance framework and processes. The use of semi-structured interviews allowed us to better understand the perspectives of these actors on the changes in governance structure and organizational design that occurred after the merger process. The roles of the interviewees who participated in the present study are presented in Table 1.

Three researchers conducted interviews from March to June 2018, and all researchers participated in all interviews. The duration of the interviews ranged from one to two hours for a total of approximately $35 \mathrm{~h}$ of recorded interviews. Finally, an additional face-to-face meeting with the same CEOs involved in the first meeting was conducted to discuss and validate the data after analysis. Discussions and comments on the meetings were collected through handwritten notes.

\subsection{Data analysis}

Descriptive coding was used to analyze the data. All interviews were fully transcribed by one researcher, after which all researchers met together to discuss and define coding and themes, until consensus was finally achieved. Thereafter, the main topics of significant passages of the interviews were synthesized, and the answers of interviewees in the same/different roles and organizations were compared using the constant comparative method (Boeije, 2002). Next, all researchers compared the results of the interviews with the documents collected from the organizations, to assess their consistency. The comparison and synthesis of interviews, observations, archival documents, and secondary sources, according to methods by Lambotte and Meunier (2013), allowed for the creation of a framework from broad and varied sources (Denzin \& Lincoln, 2011). Integrating these different sources enabled 
researchers to better understand the governance structures and organizational design of the three cases (Jennings et al., 2010).

The most significant statements made by the interviewees are presented in the results section. The participants also provided information that allowed researchers to identify the most important elements contained in the collected documents. Data for each case were derived from the collected documents and interviews, stored, and summarized in separate files. The findings were examined both within each case and among the three cases.

\subsection{Case descriptions}

The Rome 1 LHO was created in 2016 after two merger processes. First, the independent hospital San Filippo Neri was incorporated into the Rome E LHO. Subsequently, Rome E was merged with Rome A. Rome 1 was the resulting entity of all mergers. It serves half of the municipality and population of Rome, providing services to many tourists and commuter workers. It is geographically concentrated and densely populated. The primary sources of services offered are public and accredited private providers, from which the LHO purchases services. This explains the relatively high ratio of total revenue for unit of staff of $€ 520$ thousand (Table 2). The CEO has a managerial and sociological background and previously served as a CEO in one of the organizations involved in the merger process (Rome E). The merger that resulted in the creation of the Rome 1 LHO was a long and progressive process that was led by an explicit institutional redesign of the healthcare system in the urban context of the capital. Besides of the large proportion of the production processes carried out by external providers, another factor of external complexity, is the numerosity and heterogeneity of the stakeholders and the intensity of their expectations (a capital city, including the Vatican City).

The Central Tuscany LHO was created in 2016 as part of the reorganization of the regional public healthcare system. It was the result of a merger between four previous LHOs: Florence, Pistoia, Prato, and Empoli. This LHO can be more accurately described as a sub-regional entity rather than as a local organization. It serves 77 municipalities, accounting for approximately 1,600,000 inhabitants served by ten hospitals. Its primary function is service production, with a total revenue for unit of staff of $€ 199$ thousand. The geographical coverage area, number of municipalities, number of hospitals, and primary function of service production determine the need for a more complex organizational chart. In fact, the number of units in this LHO are double that of the Rome 1 LHO and three times that of the City of Turin LHO. The CEO has a medical background and was previously the CEO of one of the merged organizations (Florence LHO). The merger process leading to the present LHO was the result of a political decision to radically reform the institutional framework of the regional healthcare system. The new LHO is complex, in terms of the population served, geographical extension, and internally produced services. At the same time, a territory made of 75 municipalities multiplies the number of institutional actors involved in the decision-making process, adding external factors to its complexity. 





The city of Turin LHO was established in 2017 as a consequence of the mergers of Turin 1 and Turin 2 LHOs. The organization serves the entire territory of the Turin municipality. The geographical area is limited to the city, but is densely populated. It is the smallest among the three LHOs in this study, with half the population of Central Tuscany, three hospitals, and 120 organizational units. The services offered to the population are the result of a balanced mix of internal production and external purchasing, with a total revenue for unit of staff of $€ 327$ thousand. The CEO of the City of Turin LHO has a medical background and had previously served as the CEO of the Turin 2 LHO. In the city of Turin LHO, the merger process started with the resignation of the CEO of one of the two previous LHOs of the city. This made it possible to adopt a new institutional design by merging the two local LHOs covering the city area. Notwithstanding the speed of the merger process imposed by regional authorities, the integration was facilitated by the two organizations sharing the same general environment (in terms of social context, needs, and institutional and political stakeholders) and main external actors.

Table 2 summarizes the important characteristics of the three LHOs and their populations.

\section{Results}

Across the three cases, the TMTs adopted different models of governance to cope with the new situation. The changes that we observed are presented and interpreted based on the two domains of changes at the CHQ proposed by Kunisch et al. (2015):

- Organizational design choices within the strategic apex (especially the CHQ) and operating lines;

- The strategy domain refers to choices adopted by the CEO, including the distribution of responsibility among the actors of the organization.

\subsection{Organizational design choices}

The Rome 1 LHO opted to strengthen the strategic apex through the reorganization and departmentalization of the CHQ. With regard to the functioning of the strategic apex, the role of the CHQ was visibly reinforced and, at the same time, the strategic apex itself was more clearly separated from the operating lines.

"The Structure is divided into Central Services-that create value for the organization-and Services to the citizen-that create value for the population." (Company Act of Rome 1 LHO).

The reorganization of the techno-structure inside the CHQ was part of the same design that aimed to provide adequate support to the TMT. In particular, a "department of organizational development", dedicated to serving the TMT, was created with a focused mission: 
"...to put into a single container all the functions required to run the strategic government of an LHO, through the production of knowledge, analysis, and evaluation elements, but also of support functions to the TMT in the management of institutional relations and in the formulation of strategic choices. From this perspective, the department of organizational development constitutes the instrument to make the LHO functioning easier to read, to point out a few critical flaws and to propose to the TMT the necessary and most appropriate technical solutions to improve corporate responses and to ensure economic sustainability." (Company Act of Rome 1 LHO).

In the Central Tuscany LHO, characterized by a larger geographical dispersion, the CEO opted for the reinforcement of pre-existing department structures based on clinical specialties. The chiefs of each departments (CoDs) expanded their responsibilities as managers of the divisions. This facilitated the reorganization in terms of the focalization of the strategic apex.

"I'm not used to delegating. However, this was necessary. I departmentalized the organizational design and delegated many functions. To make all that workable, I needed to build a managerial group who can stand on its own." (CEO)

"The participation of the departmental line and, as a consequence, of the Chair of Department, to strategic choices has been encouraged. In fact, it's all up to him." (CoD)

To strengthen the departmentalized structure, a new level was added through the creation of areas. Areas represent a type of subunit or subdivision that brings together the disciplines that are most related to each other within a department. This decision was justified by the need to tackle the widespread dispersion of the activities of a department across a large geographical area, homogenize the service standard, and improve the quality of care.

With regard to the City of Turin LHO, the usual configuration of the TMT as a triad (CEO, CD, and AD) was enriched by five other formal roles: two coordinators of the lines (one for the territorial area and the other for the hospital area) and three staff coordinators (planning and development, support, and management and control). Thus, the CEO of the City of Turin LHO enlarged its strategic apex in an attempt to ensure direct supervision of the TMT over a larger organization. The redesign of the strategic apex facilitated greater specialization within the CHQ and resulted in greater integration with intermediate lines, thereby resulting in better control of the lines.

"I've been believing for many years that the triad (CEO-CD-AD) alone doesn't work in coping with the complexity, in particular, in an LHO of such size. That's why I've implemented a mechanism to enlarge the triad (the TMT) that in their traditional configuration didn't work anymore and had become a 'bottleneck' on the decision-making processes. I have come up with an alternative to support the CEO with other figures. In this way, the power is distributed in the LHO according to specific needs. I have 
attempted to overcome the triad organization with the inclusion of coordinating figures, participating in strategic governance." (CEO)

The coordinators became a part of the TMT, and they received a specific mandate from the CEO to manage relevant processes or projects. The coordinator of the planning and development functions played an important role in supporting strategic objectives.

"The coordinators promote the implementation of the strategic direction/ behavior within the activities they coordinate; they are also responsible for guaranteeing the integration and interconnection between the activities supervised by the other coordinators." (Company Act of the city of Turin, LHO).

"The coordinator of plans and development functions plays an active role in the first level of strategic governance as technical support to identify the addresses and strategic objectives." (Company Act of the city of Turin, LHO).

\subsection{Strategy domain (roles and managerial styles)}

The CEO of Rome 1 LHO considers change to be a structural component for any organization, not only for those experiencing a merger process. From this perspective, strategy implies change management at each stage. He believes that one of the main responsibilities of the CEO is to promote and accomplish change. The reorganization of the CHQ was accompanied by a more defined and specialized role for the three components of the TMT triad. In this context, the CEO's role is more oriented toward the management of relationships with external stakeholders and change management. In this regard, CHQ plays an important role in supporting TMT.

"I have always thought my role as connected with change management... with, outward, the need to give the LHO a strong identity and, inward, to create a system in which responsibilities are clear while processes and activities are able to assure an adequate control of the overall organization, letting me focus on the strategy process." (CEO)

The interviews revealed that the middle managers (MMs) consequently believed that they were assigned greater responsibilities and were required to play a stronger coordinating role.

"Historically, the department director had a merely formal role. Now, on the contrary, they are called on to represent the bridge between the strategic apex and the operating lines within an LHO where department represents the backbone of the organization." (CoD)

In the Central Tuscany LHO, the process of selecting and training a group of managers facilitated the implementation of the aforementioned organizational changes. The team building process benefited from the trust shared between the CEO and the 
CoDs. The new governance model aimed to endow CoDs with greater responsibilities with regard to strategic decision-making.

"My staff is composed of all the CoDs, area directors, district-zones directors. I meet them frequently, not only in formal meetings." (CEO)

As a result of this process, TMT effort is mainly devoted to the coordination of divisional strategies. The simplification of internal supervision allowed the CEO to focus on external relationships in the arena in which political and institutional consensus is gained or lost.

The CoDs are cognizant of their major roles:

"The CEO expects me to adopt a strategic role too. Now, I do more than I would have done before. The responsibility of a chief department is to support the CEO in the strategic government." (CoD)

In this situation the CEO considers CoDs as an extension of the strategic apex.

"I think that, in this process, we can consider MMs as the extension of the TMT in particular of AD and CD. At present, in fact, MMs actually manage processes and professionals, and at the same time, cooperate closely with me and support me." (CEO)

In the City of Turin LHO, the formal inclusion of the newly appointed coordinators in the TMT enlarged the TMT, expanding the control of the TMT on the departments. This process of concentration shortened the distance between the strategic apex and the lines, weakening the boundaries that usually separate top and middle management.

"The TMT enlargement through the coordinators made it possible to attract the head of departments in the sphere of TMT... I enlarged the strategic government of the organization... This new governance model has been designed having in mind the problem of how to involve all the middle management roles." (CEO)

Table 3 presents the major differences in the variables that emerged between the cases.

\section{Discussion}

We applied a contingency approach to the studies of organizations with a monocratic governance framework (Toth, 2015). In doing so, we referred to the call for studies that analyze the role of governance structures in situations where governance actors can play non-traditional roles, depending on the institutional context (Ambos \& Müller-Stewens, 2017). In such situations, we found that TMTs have to oversee two categories of external governance areas.

The first category, considered as the typical external focus of a board in healthcare organizations (Lee et al., 2008), can be labeled as external institutional. This 


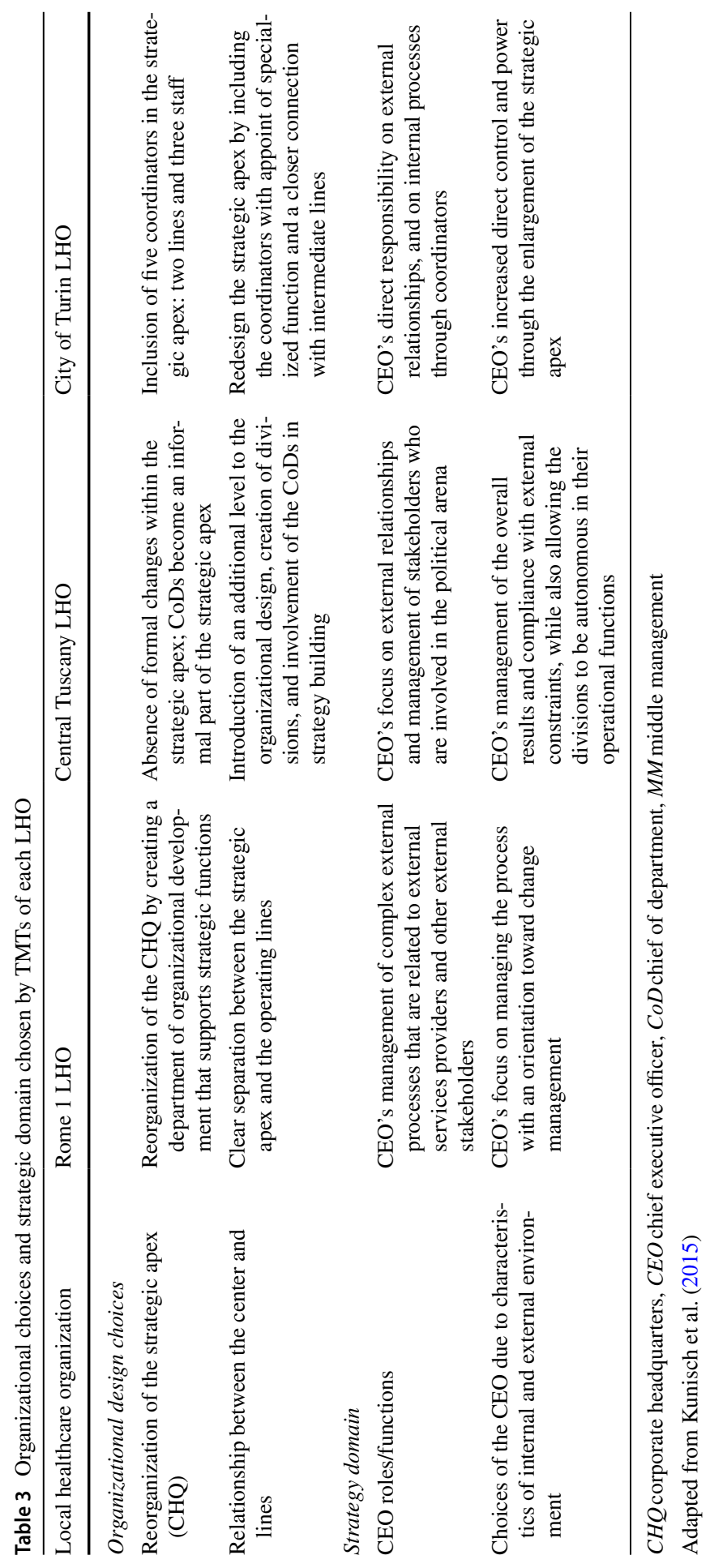


category covers dialog with political and institutional stakeholders who represent the interests of the community at large. Since consensus plays an important role in the functioning of public organizations, it is a crucial area that has implications for the success of an LHO. The intensity of institutional- and consensus-related needs that call for the attention of the TMT depends on many variables: the institutional framework, number of actors involved, cohesion of the community, and nature and dynamics of associated political systems.

However, in the cases we analyzed, we also found that TMTs cover a second category, which we call external integrative. This category is related to the governance of indirect service provision, which refers to the management of accredited services and relationships with other public institutions that provide healthcare services to the same population (typically, independent public hospitals). It is a critical area whose importance can vary depending on the specific regional healthcare system. Here, administrative processes located at the CHQ level are causally linked to the strategic objective of providing services and play a pivotal role in the success of LHOs.

In the cases we analyzed, the internal governance area (Cornforth, 2003), was managed by the CEO and TMT. We call this category internal organizational. This category pertains to the production and direct provision of services to citizens and patients. Merger processes and consequent larger sized organizations pose challenges in terms of professional and operational coordination, homogeneity of service standards, and the search for synergies and cost reduction. This focus concerns the control of the organization's operating cores along managerial lines and the supervision of their overall functioning.

The cases show how merger processes and the subsequent increase in organizational size affect the different areas that claim the attention of governing structures. Usually, these areas in other healthcare systems and governance frameworks are under the joint responsibility of multiple actors and the board plays a significant role (Lee et al., 2008). In this context, we study the CEO and its TMT, covering all three governance areas.

The case of Rome 1 LHO is different from that of other large urban LHOs nationwide. Given the characteristics of the external environment, that is, the numerosity and heterogeneity of stakeholders and the intensity of their expectations, and the important role of independent and public and private accredited providers, the main challenges that confront the TMT stem from the institutional and consensus-related and integrative dimensions. Variations in both these areas require significant changes in the role and capacity of the TMT. More time and greater attention, especially on the part of the CEO, should be devoted to the direct management of relationships with external stakeholders (i.e., those linked to consensus). Additionally, relationships with external independent providers (integrative focus) are typically managed with the support of the administrative component of the CHQ. However, the critical role that such relationships play (which is partly related to the commissioning process, albeit with relevant political-institutional consequences) imposes an intense involvement and keen surveillance on the part of the TMT. Moreover, Rome 1 LHO is the result of a long and progressive merger process guided by an explicit institutional design. From this point of view, the interpretation of the role of CEO, mainly 
in terms of change management, certainly originates from the vision and curriculum of the CEO, but is reinforced by an explicit design of the institutional evolution that has to be accomplished. Since enhanced efficiency can be helpful for TMTs overloaded with responsibilities, TMT capabilities of control over the internal production lines and external indirect provision have been expanded by strengthening the CHQ (also in terms of size and responsibility), so that they can support the TMT's decisions (Menz, 2012). These changes have been accompanied by a more definite division of tasks within the triad. Specifically, the CEO focused on external matters and change management, whereas $\mathrm{CD}$ and $\mathrm{AD}$ were primarily responsible for managing internal matters. Such specializations were made possible by the stability of the TMT and the development of a climate of mutual trust among its members.

Central Tuscany LHO differs substantially from the other two LHOs. This LHO does not merely represent an improvement in existing organizations. Instead, it is a completely new entity, and its underlying vision has been subject to significant redesign. The creation of the Central Tuscany LHO was the result of a reform of the regional system, which did not touch the overall institutional architecture of the LHOs (mission and formal governance structure) but radically altered their size, moving from a local to a sub-regional level. This changed the magnitude of institutional, consensus-related, and internal complexity (indirect provision is negligible in Tuscany, and there are only four independent public teaching hospitals). From an external institutional point of view, the multiplication of the communities served increased not only the number of stakeholders relevant to the decision-making process, but also the spectrum of interests that must be considered. Moreover, as one of the only three Tuscan LHOs, the Central Tuscany LHO and its TMT are now at a crucial intersection between regional governments and municipalities. This is an intersection where the distinction between managerial and political spheres is often unclear, and the role of the CEO is of fundamental importance. From an internal point of view, the search for economies of scale and greater homogeneity in the standard of care were important objectives of the reform to be pursued through strong coordination across physically and geographically dispersed production processes. Decentralization has been the CEO's response to new emergent needs (Ferlie \& Pettigrew, 1996). He assigned full responsibility to large divisions based on clinical and professional homogeneity. This gave the CEO the possibility of focusing his attention on the institutional external dimension. In the Central Tuscany LHO, the roles of the TMT and CHQ are those expected in a divisionalized organization: providing directions to the divisions, assuming the responsibility of engaging in a dialog with the external environment, and managing the large centralized administrative processes that are typical of public organizations, which is comparable to a steering mode that some authors name the strategic planning style (Dossi et al., 2017).

A key visible element of the Central Tuscany LHO's functioning is the close, trust-based relationship between the TMT, the CEO in particular, and the heads of the divisions. Underlying the deliberate choice to use consensus and trust as a distinctive trait of the governance framework is the recognition that divisionalized forms in professional organizations are complex to implement because managerial controls may be weak in comparison to the controls of hybrid managers (CoDs). 
Trust and consensus are the result of many different factors. They are partially contingent on external environmental factors, such as local culture, and politicalinstitutional stability and continuity. However, managerial style remains a crucial component. In this regard, the TMT devotes a lot of attention and energy into cultivating personal relationships with middle management, in general, and the heads of departments, in particular. They seek to promote and encourage collective discussion. The overall picture of the governance framework that is in place at the Central Tuscany LHO is reminiscent of a very polarized system in which intense organizational decentralization makes it possible for the TMT to focus on the management of institutional and consensus-related complexities. At the same time, the peculiar nature of the relationships between the TMT and Chief of Departments facilitates the alignment of the behavior of largely autonomous divisions that implement corporate strategies (which is a relevant component of the responsibilities of the strategic apex).

As a result of the merger process, the LHO in Turin almost doubled in size. This change affected its governance areas to different extents. The main differential impact was in the area of production and the direct provision of services. As a consequence of the merger process, this area experienced a significant size increase, while both the scenarios of the institutional-political stakeholders (institutional and consensus-related dimension) and other service providers (integrative dimension) remained basically the same, in comparative terms. At the same time, the institutional dynamics of the merger process, which was a spot decision prompted by a casual event, such as the resignation of the CEO of the other LHO in the city, did not convey any sense of need for a change organization, except with regard to the functioning of the productive engine. In this situation, the CEO directed the readjustment of the strategic apex in such a manner that he could gain better control of a larger machine through a substantial expansion of the size of the TMT. In this way, he strengthened the central control of the organization, a decision opposed to that taken by Tuscany's CEO (Ferlie \& Pettigrew, 1996). Overall functioning, in terms of the mechanisms of a new and enlarged $\mathrm{CHQ}$, remained unchanged. Instead, attention was focused on the capacity of the TMT to adapt to a new extension of the internal area to be controlled. This can be interpreted as an isomorphic response to a new condition in which the most important potential bottleneck that had been included in the design was the ability of the TMT to continue to exert the same degree of direct control over the production lines in a situation that was modified.

As shown by the cases discussed, after a merger process, it is the TMT that has to readjust its way of functioning and re-balance its attention among the three different areas. Depending on the specific context, the magnitude of the impact of a merger on each of the three areas may differ. At the same time, each TMT may assign different priorities to the areas and reconfigure the strategic apex and its functioning to face a new situation (Menz, 2012). As Donaldson (2001) underlines, a change in the environmental and organizational context, in this case of the merger process, is followed by a reconfiguration of the strategic apex. The specific approach followed in such a change in a fundamental piece of the governance structure, depends on the type and degree of change in the internal and external environment (Foss, 1997) 
and, in particular, on the modification of the levels of complexity of the environment (Alexander, 1991).

Our analysis also confirms that, to better understand the overall transformation of the organization after a merger (Ferlie \& Pettigrew, 1996), it is important to look inside the internal organizational institutional environment, particularly to the steering modes (Dossi et al., 2017). In addition, we found that vision is another component that leads the CEO's governance choices.

Table 1 provides a comparative synthesis of these three cases. Facing the consequences of the new size and structure, the three LHOs re-adjusted their governance strategies and mechanisms. Rome 1 strengthened the strategic apex in terms of support that the CHQ, and staff in particular, could offer to the TMT in the area of external governance, for both institutional and integrative components. This choice reflects the intensity of the externally oriented effort required of the TMT, and the change management approach to the governance of the internal environment, that requires a direct and well-supported CEO, who cannot delegate certain responsibilities to ordinary managerial lines. In the Tuscany case, a focalization of the TMT on the only relevant component of the external dimension, the institutional one, has been made possible through the clear decentralization by the creation of divisions, which was facilitated by the cultural homogeneity in the organizational environment. The choice in the Turin case was to enlarge the strategic apex, expanding the possibilities of the TMT to directly control the lines of internal production. The strategy of focalization on the internal dimension through direct supervision of the lines responds to a situation in which the variation in external needs is felt by the CEO as less demanding than the internal ones, and the LHO's limited geographical extension facilitates direct supervision. Therefore, we observed that the transformation processes generated by mergers can follow different paths in redesigning corporate centers (Goold et al., 2001; Kunisch et al., 2015). Turin LHO tries to strengthen central capabilities to control an enlarged organization, while others decentralize by providing a higher degree of authority to lower levels of the organization, saving the TMTs energies for different tasks (Ferlie \& Pettigrew, 1996).

From a managerial point of view, the study suggests that the role and functioning of the strategic apex can be seen from the top management as an area of intentional intervention. In public organizations, corporate governance is usually regarded as an exclusive domain of political-institutional decision-making. The cases show how, even within a fixed institutional framework, the role can be modeled and clarify which strategies may be followed in doing so. This confirms that, in the cases of fixed institutional frameworks, the context should guide which theory and relative mechanisms of governance adopt to better fit the circumstances (Chambers et al., 2020).

Table 4 presents a comparison of the cases in terms of the impact of the merger on governance areas and the governance strategy chosen by the strategic apex. 
Table 4 Merger impacts on governance areas and the governance strategy chosen by strategic apex across the local health organizations in the Rome 1, Central Tuscany, City of Turin

\begin{tabular}{llcc}
\hline $\begin{array}{l}\text { LOCAL HEALTHCARE } \\
\text { ORGANIZATION }\end{array}$ & \multirow{2}{*}{ ROME 1 LHO } & $\begin{array}{c}\text { CENTRAL } \\
\text { TUSCANY LHO }\end{array}$ & $\begin{array}{c}\text { CITY OF TURIN } \\
\text { LHO }\end{array}$ \\
\hline MERGER IMPACTS ON & & &
\end{tabular}

MERGER IMPACTS ON GOVERNANCE AREAS

$\begin{array}{lll}\text { Internal organizational } & \begin{array}{l}\text { Limited number of } \\ \text { services directly } \\ \text { produced (mostly non- } \\ \text { hospital based). } \\ \text { (Population: }\end{array} & \begin{array}{l}\text { Widespread physical } \\ \text { and geographical } \\ \text { dispersion of the } \\ \text { production processes. } \\ \text { (Population: }\end{array} \\ \begin{array}{ll}\text { Staff: 5,600) } \\ \text { Low }\end{array} & \begin{array}{l}1,627,964 ; \\ \text { Staff: 15,000) }\end{array} \\ & \text { Low } & \text { Low High }\end{array}$

External institutional

External integrative

GOVERNANCE STRATEGY (organizational design and strategy domain

Multiple institutional stakeholders (wide territorial coverage, high number of municipalities)

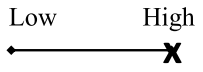

Important role of independent and public and private accredited providers in terms of total production of services. (Value of the services provided/staff: $€$ 511,583)

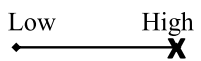

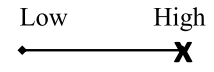

Negligible role of indirect providers in terms of total production of services. (Value of the services provided/staff: $€$ 194,752)

$\begin{array}{ll}\begin{array}{l}\text { STRENGTHENING } \\ \text { of the strategic apex }\end{array} & \text { FOCUSING of the } \\ \text { with a reorganization } & \text { strategic apex on } \\ \text { of the CHQ to cope } & \text { external relationship } \\ \text { with the increase in } & \text { through the creation of } \\ \text { external complexity } & \text { divisions to cope with } \\ \text { (especially integrative) } & \text { internal complexity }\end{array}$

The size of the internal production processes doubled (merger of similar organizations). (Population: 884,733; Staff: 5,600)

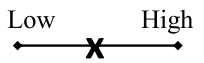

A single community is served (only one mayor) and there is only one single public health organization (that has incorporated a teaching hospital)

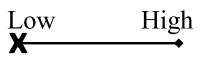

Negligible role of indirect providers in terms of total production of services. (Value of the services provided/staff: $€ 275,685$ )

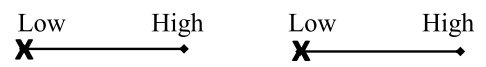

ENLARGEMENT of the strategic apex, including five coordinators with a broader specialization

\section{Conclusion}

Based on the observation that governance structures and processes could not be standardized, Alexander (1990) recommended that future studies on governance in healthcare organizations should explore the dynamics between governance structures and contingency variables. We followed this suggestion by exploring the roles 
of top managers in governance policies and practices (Tihanyi et al., 2014) in the case of Italian LHOs. The literature shows that the role of a board in healthcare organizations can be focused on internal issues or external relations on the basis of organizational and environmental conditions, and can share part of such responsibilities with top managers (Chambers et al., 2020; Cornforth, 2003). These studies did not analyze such aspects in monocratic governance models. We attempted to cover part of this gap in the literature.

Governance structures and processes respond to certain needs in different governance areas. These areas are typically overseen by means of a joint action between the governing board and the TMT, even if the two organizational actors usually maintain different perspectives on the same area and may respond in different ways (Eeckloo et al., 2004). In the monocratic governance models we analyzed, the TMT and the $\mathrm{CEO}$, in particular, have to assume full responsibility in all three areas of governance. This affects not only the governance framework but also its dynamics. In fact, when governance needs increase, the CEO and its TMT have to select the priority governance area that requires personal and direct attention over those where other mechanisms can work.

Thus, the first contribution of this paper is a better definition of the governance areas (Lee et al., 2008) in relation to possible changes in governance structures and processes. The results of this study highlight the importance of distinguishing between different governance areas, when examining the effect of an increase in the size of public organizations. The role and dynamics of external areas were of particular interest in the present study. The external environment plays a dual role in public organizations, especially healthcare organizations. It represents the market for their services. Therefore, any extension of the catchment area inevitably affects internal and/or integrative areas. Additionally, the external environment is often a part of the ownership of the organization, albeit to varying degrees. It influences decisions about which interests and objectives must be pursued and achieved. As noted in an earlier instance, the impact of geographical enlargement on institutional and consensus-related areas was found to be contingent on many different factors, varying from particularly important to negligible.

A second contribution of this paper comes from the definition and analysis of possible strategies that public healthcare organizations' TMTs may adopt in the field of organizational design and strategy (Kunisch et al., 2015). The observed strategies were defined as the enlargement, focalization, and strengthening of the strategic apex. Decisions pertaining to the reconfiguration of the strategic apex are the result of many factors that can be analyzed from different perspectives (Donaldson, 2001; Foss, 1997). Given the context of the present study and the specific cases we examined, it can be assumed that changes in the overall functioning of the strategic center were an intentional response from the CEOs to the increase in size that resulted from merger processes. However, the options available to each organization were not completely open. Indeed, several factors, which range from institutional rules to traditional practices and the capabilities of a single entity, limited their options. The merger of two or more LHOs into a single organization not only increases the overall complexity that the strategic apex is required to cope with, but may also require readjustment of the attention paid to different governance areas. Therefore, a radical 
change in the size of an organization may serve as an occasion for observing the modifications made to the framework and mechanisms that characterize the strategic apex. These modifications reflect the different priorities and needs of the TMT. Based on the notion that LHOs' governance structures are confronted with three different areas of governance that the TMT can choose to focus on (external institutional and consensus-related, external integrative, and internal) and that changes in the dimension of an LHO can differentially impact each area depending on specific conditions, this study delineated how the TMTs react and adapt to these changes.

A third contribution of the current study is the analysis of the antecedents of the choices of TMTs on governance. The literature underlines the importance of considering internal and external antecedents for changes in the CHQ and to the strategic apex, in general (Goold et al., 2001). The three cases investigated show how healthcare organizations, facing an increase in the complexity of the internal and external environment, implement different internal steering modes as a consequence of the prevalent focus chosen by TMT (Dossi et al., 2017). The reason for the emergence of a solution is unclear, even though the influence of the CEO's managerial experience and style as well as the role of the opportunities offered by a specific context were recognizable for each case.

The final contribution concerns non-formal governance processes. The possibility of altering the structure and formal roles of the TMT and CHQ in the LHOs' case is quite limited because they are defined by regional and national laws. Moreover, it is almost impossible for LHOs to sustain a new configuration with fresh resources and new managers (paradoxically, this is also true for organizations that easily exceed half a billion euros in costs). Even if there was no opportunity to make radical changes, the adjustments introduced by the CEOs were highly significant. They were required to operate within tight constraints, albeit on the basis of a recognizable vision of the corporate center that they needed. Nevertheless, they changed the key elements in the strategic domain and in the field of organizational decision-making. These observations underscore the importance of the TMT in designing its role and identifying the main mechanisms that must be used to control the organization. Therefore, with regard to public organizations, the relationship between the formal (institutionally defined) structure of governance and managerial behaviors must be reconsidered, as also suggested by Veronesi and Keasey (2010). In particular, the larger autonomy of management when compared to institutional design must be considered. Our study confirms the importance of looking at non-formal governance processes along with formal ones using a contingency approach, as recommended in the literature (Erwin et al., 2019).

A limitation of this study pertains to the number of cases examined. On one hand, the examination of three LHOs facilitated the execution of in-depth analyses, but, on the other hand, larger samples are required to extend beyond exploratory analysis and ground the conclusions of the present study in a more concrete way. However, it must be recognized that there is a gap in the literature about the role of the TMT and the strategic apex in general, in investigations on public healthcare organizations. Typically, in the case of public organizations, attention is focused on institutional corporate governance, rather than on the governance of the organization as a process 
that results from the interaction between a formal structure and the behaviors of the actors.

\section{Appendix}

\section{Semi-structured interview protocol}

\section{CEO}

- What are the main reasons for the merger and the main phases in the process?

- How has your role changed in the different phases?

- How has the external environment changed after the merger?

- How has the internal environment changed after the merger?

- How did you balance between external and internal needs?

- Which innovations have you introduced in terms of:

- Governance arrangements;

- Managerial tools;

- Organizational design?

- How have relationships in the TMT changed?

- How have relationships with MMs changed?

\section{Middle management}

- Could you describe how your organization has changed in the last few years?

- Do you think that CEO's expectations for your role has changed?

- How has your role changed after the merger?

- Do you think that your contribution to the organization strategy has increased?

Funding This study was funded by FIASO (Federazione Italiana Aziende Sanitarie e Ospedaliere).

\section{Declarations}

Conflict of interest We have received research grants from FIASO (Federazione Italiana Aziende Sanitarie e Ospedaliere). The authors declare that they have no conflict of interest.

Open Access This article is licensed under a Creative Commons Attribution 4.0 International License, which permits use, sharing, adaptation, distribution and reproduction in any medium or format, as long as you give appropriate credit to the original author(s) and the source, provide a link to the Creative Commons licence, and indicate if changes were made. The images or other third party material in this article are included in the article's Creative Commons licence, unless indicated otherwise in a credit line to the material. If material is not included in the article's Creative Commons licence and your intended use is not permitted by statutory regulation or exceeds the permitted use, you will need to obtain permission directly from the copyright holder. To view a copy of this licence, visit http://creativecommons.org/licen ses/by/4.0/. 


\section{References}

Alexander, J. A. (1990). Governance for whom? The dilemmas of change and effectiveness in hospital boards. Frontiers of Health Services Management, 6(3), 38-41.

Alexander, J. A. (1991). Adaptive change in corporate control practices. The Academy of Management Journal, 34(1), 162-93.

Alexander, J. A., \& Lee, S. Y. (2006). Does governance matter? Board configuration and performance in not-for-profit hospitals. The Milbank Quarterly, 84(4), 733-758.

Ambos, T., \& Müller-Stewens, G. (2017). Rethinking the role of the centre in the multidivisional firm: A retrospective. Long Range Planning, 50, 8-16.

Ancona, D. G., Goodman, P. S., Lawrence, B. S., \& Tushman, M. L. (2001). Time: A new research lens. Academy of management Review, 26(4), 645-663.

Ashburner, L. (2003). The impact of new governance structures in the NHS. In C. Cornforth (Ed.), The governance of public and non-profit organisations-What do boards do? (pp. 207-220). Routledge.

Barzan, E., Borsoi, L., Gugiatti, A., \& Petracca, F. (2018). La Struttura e le Attività Del SSN. In Rapporto Oasi 2018. Osservatorio sulle aziende e sul sistema sanitario italiano. Egea.

Boeije, H. (2002). A purposeful approach to the constant comparative method in the analysis of qualitative interviews. Quality \& Quantity, 36, 391-409.

Carpenter, M. A., Geletkanycz, M. A., \& Sanders, W. G. (2004). Upper echelons research revisited: Antecedents, elements, and consequences of top management team composition. Journal of Management, 30(6), 749-778.

Carver, J. (2006). Boards that make a difference: A new design for leadership in nonprofit and public organizations. Wiley.

Chambers, N., Smith, J., Proudlove, N., Thorlby, R., Kendrick, H., \& Mannion, R. (2020). Roles and behaviours of diligent and dynamic healthcare boards. Health Services Management Research, 33(2), 96-108.

Chandler, A. D. (1991). The functions of the HQ unit in the multibusiness firm. Strategic Management Journal, 12(S2), 31-50.

Ciabuschi, F., Dellestrand, H., \& Holm, U. (2012). The role of headquarters in the contemporary MNC. Journal of International Management, 18(3), 213-223.

Cibin, R., \& Grant, R. (1996). Restructuring among the world's leading oil companies, 1980-92. British Journal of Management, 7(4), 283-307.

Collis, D., Young, D., \& Goold, M. (2007). The size, structure, and performance of corporate headquarters. Strategic Management Journal, 28(4), 383-405.

Cornforth, C. (2003). The changing context of governance-Emerging issues and paradoxes. In C. Cornforth (Ed.), The governance of public and non-profit organisations: What do boards do? (pp. 1-19). Routledge.

Del Vecchio, M. (2000). La programmazione strategica nelle aziende sanitarie. In G. Casati (Ed.), Programmazione e controllo di gestione nelle aziende sanitarie (pp. 13-38). McGraw-Hill.

Del Vecchio, M., \& Romiti, A. (2017). Prospettive di sviluppo per la governance delle aziende sanitarie. In M. Del Vecchio, N. Pinelli, F. Ripa di Meana, A. Romiti, \& A. Tanese (Eds.), Aziende e management per il futuro del SSN (pp. 45-68). KOS Comunicazione e Servizi s.r.l.

Denzin, N. K., \& Lincoln, Y. S. (2011). Disciplining the practice of qualitative research. In N. K. Denzin \& Y. S. Lincoln (Eds.), The Sage handbook of qualitative research (pp. 1-20). Sage.

Donaldson, L. (2001). The contingency theory of organisations. Sage.

Dossi, A., Lecci, F., Longo, F., \& Morelli, M. (2017). Hospital acquisitions, parenting styles and management accounting change: An institutional perspective. Health Services Management Research, $30(1), 22-33$

Edwards, C., \& Cornforth, C. (2002). What influences the strategic contribution of boards? In C. Cornforth (Ed.), The governance of public and non-profit organizations (pp. 89-108). Routledge.

Eeckloo, K., Delesie, L., \& Vleugels, A. (2007). Where is the pilot? The changing shapes of governance in the European Hospital Sector. Journal of the Royal Society for the Promotion of Health, 127(2), 78-86.

Eeckloo, K., Van Herck, G., Van Hulle, C., \& Vleugels, A. (2004). From corporate governance to hospital governance. Authority, transparency and accountability of Belgian non-profit hospitals' board and management. Health Policy, 68(1), 1-15. 
Eisenhardt, K. (1989). Building theories from case study research. The Academy of Management Review, 14(4), 532-550.

Erwin, C. O., Landry, A. Y., Livingston, A. C., \& Dias, A. (2019). Effective governance and hospital boards revisited: Reflections on 25 years of research. Medical Care Research and Review, 76(2), $131-166$.

Ferlie, E., Hartley, J., \& Martin, S. (2003). Changing public service organizations: Current perspectives and future prospects. British Journal of Management, 14, S1-S14.

Ferlie, E., \& Pettigrew, A. (1996). Managing through networks: Some issues and implications for NHS. British Journal of Management, 7(s1), S81-S99.

Forbes, D., \& Milliken, F. (1999). Cognition and corporate governance: Understanding boards of directors as strategic decision-making groups. The Academy of Management Review, 24(3), 489-505.

Foss, N. (1997). On the rationales of corporate headquarters. Industrial and Corporate Change, 6(2), 313-338.

Golden, B. R., \& Zajac, E. J. (2001). When will boards influence strategy? Inclination $\times$ power $=$ strategic change. Strategic Management Journal, 22(12), 1087-1111.

Goodstein, J., \& Boeker, W. (1991). Turbulence at the top: A new perspective on governance structure changes and strategic change. Academy of Management Journal, 34(2), 306-330.

Goold, M., \& Campbell, A. (1987). Strategies and styles: The role of the centre in managing diversified corporations. Blackwell.

Goold, M., Pettifer, D., \& Young, D. (2001). Redesigning the corporate centre. European Management Journal, 19(1), 83-91.

Harris, M. (1992). The role of voluntary management committees. In J. Batsleer, C. Cornforth, \& R. Paton (Eds.), Issues in voluntary and non-profit management. Open University/Addison-Wesley.

Jarzabkowski, P., Balogun, J., \& Seidl, D. (2007). Strategizing: The challenges of a practice perspective. Human Relations, 60(1), 5-27.

Jennings, G., Kensbock, S., Junek, O., Radel, K., \& Kachel, U. (2010). Lived experiences of early career researchers: Learning about and doing grounded theory. Journal of Hospitality and Tourism Management, 17(1), 21-33.

Kirkpatrick, I., Bullinger, B., Lega, F., \& Dent, M. (2013). The translation of hospital management models in European health systems: A framework for comparison. British Journal of Management, 24(S3), S48-S61.

Kunisch, S., Menz, M., \& Ambos, B. (2015). Changes at corporate headquarters: Review, integration and future research. International Journal of Management Reviews, 17(3), 356-381.

Lambotte, F., \& Meunier, D. (2013). From bricolage to thickness: Making the most of the messiness of research narratives. Qualitative Research in Organizations and Management, 8(1), 85-100.

Lee, S. Y. D., Alexander, J. A., Wang, V., Margolin, F. S., \& Combes, J. R. (2008). An empirical taxonomy of hospital governing board roles. Health Services Research, 43(4), 1223-1243.

Maljers, F. A. (1992). Inside unilever: The evolving transnational company. Harvard Business Review, $70(5), 46-52$.

Menz, M. (2012). Functional top management team members: A review, synthesis, and research agenda. Journal of Management, 38(1), 45-80.

Ministry of Health. (2017). Demographic context: Resident population 31 December 2017. Retrieved February 9, 2019, from http://www.salute.gov.it/portale/documentazione/p6_2_8_3_1.jsp?lingua= italiano\&id $=17$

Ministry of Health. (2018). Archive of regional economic and financial data. Retrieved May, 2020, from http://www.salute.gov.it/portale/temi/p2_6.jsp?lingua=italiano\&id=1314\&area=programmazioneS anitariaLea\&menu=dati

Mintzberg, H. (1993). Structure in fives: Designing effective organizations. Prentice-Hall, Inc.

Mintzberg, H. (2012). Managing the myths of health care. World Hospitals and Health Services: The Official Journal of the International Hospital Federation, 48(3), 4-7.

Morelli, M., \& Lecci, F. (2014). Management control systems (MCS) change and the impact of top management characteristics: The case of healthcare organisations. Journal of Management Control, 24(3), 267-298.

Pettigrew, A. M. (1987). Context and action in the transformation of the firm. Journal of Management Studies, 24(6), 649-670.

Terlizzi, A. (2019). Health system decentralization and recentralization: Ideational and institutional dynamics in Italy and Denmark. Palgrave Macmillan. 
Tihanyi, L., Graffin, S., \& George, G. (2014). Rethinking governance in management research. Academy of Management Journal, 57(6), 1535-1543.

Toth, F. (2015). Like surfers waiting for the big wave: Health care politics in Italy. Journal of Health Politics, Policy and Law, 40(5), 1001-1021.

Van de Ven, A. H., \& Poole, M. S. (1995). Explaining development and change in organizations. Academy of Management Review, 20(3), 510-540.

Veronesi, G., \& Keasey, K. (2010). NHS boards: Knowing the 'what' but not the 'how.' Public Money \& Management, 30(6), 363-370.

Yin, R. K. (2009). Case study research: Design and methods (4th ed.). Sage.

Yin, R. K., Bateman, P. G., \& Moore, G. B. (1983). Case studies and organizational innovation: Strengthening the connection. COSMOS Corporation.

Young, D., \& Goold, M. (1999). Effective headquarters staff: A guide to the size, structure and role of corporate headquarters staff. Ashridge Strategic Management Centre.

Young, G., Beekun, R. I., \& Ginn, G. O. (1992). Governing board structure, business strategy, and performance of acute care hospitals: A contingency perspective. Health Services Research, 27(4), $543-564$.

Publisher's Note Springer Nature remains neutral with regard to jurisdictional claims in published maps and institutional affiliations.

Anna Romiti is an Assistant Professor of Management at the Department of Clinical and Experimental Medicine at University of Florence where she is member of the Health Services Research Unit. Her research activities focus on Healthcare Management and Sport tourism management. She is author of numerous books and articles on her topics of interest. Her works have been published in BMC Health Services Research, Health Services Management Research, and Mecosan, among others. She is member of Editorial Board of Mecosan from 2019. She routinely collaborates with a large national association, the Italian Association of Public Healthcare (FIASO). Anna earned a degree in Economics and Management from University of Florence, Italy, in 2000.

Mario Del Vecchio is an Affiliate Professor of Government, Health and Not for Profit at SDA Bocconi School of Management. He is an Associate Professor at the Department of Clinical and Experimental Medicine at University of Florence where he is in charge of the Health Services Research Unit. At SDA Bocconi, he was the Vice Director of the "Claudio Demattè" Research Division (2004-2008) and then was Director of the Master in Healthcare Management (2010-2014). At present he is Knowledge Leader of the Observatory on Privately Financed Health Consumption. He has conducted research and education projects with major national and international firms. His research activities focus on private Privately Financed Health Consumption in Healthcare, on the institutional organization and strategic choices in public healthcare companies, planning and control in public healthcare companies and organization and human resource management in brain-intensive companies. Recently, he has been analysing four main topics: relations between public and private consumption in health care, the strategy for professional communities with nursing colleges, communication in public health units and conditions for management development in the healthcare sector in Italy. He is the author of numerous books and articles on his topics of interest. His works have been published in Health Policy, Politiche Sociali, the Italian Journal of Public Health and Mecosan, among others. He was Editor in Chief of Mecosan from 2003 to 2013 and he has taught at theNew York University.He routinely works with large national associations like the Italian Association of Public Healthcare (FIASO) or the Italian Nurses Association (IPASVI). Mario earned a degree in Economics from Università Bocconi. 
Chiara Milani is a Medical Doctor, specialist in public health. She worked in a Health District in the primary care organization during the pandemic emergency. She has a postdoctoral fellowship at Department of Health Science of the University of Florence (title of the project: Experimentation of new organizational models in primary care), Florence, Italy.

Gino Sartor is graduated in medicine and surgery, specialized in hygiene, epidemiology, preventive medicine and public health. Currently he works for the Primary Care division in a local health and social care authority. 